\title{
THE PROBLEM OF COLD STARTS: A CLOSER LOOK AT MOBILE SOURCE EMISSIONS LEVELS
}

\author{
Matthew S. Reiter \\ Department of Civil, Architectural and Environmental Engineering \\ The University of Texas at Austin - 6.9 E. Cockrell Jr. Hall \\ Austin, TX 78712-1076 \\ matthew.reiter@utexas.edu \\ Kara M. Kockelman \\ (Corresponding Author) \\ E.P. Schoch Professor of Engineering \\ Department of Civil, Architectural and Environmental Engineering \\ The University of Texas at Austin - 6.9 E. Cockrell Jr. Hall \\ Austin, TX 78712-1076 \\ kkockelm@mail.utexas.edu \\ Phone: 512-471-0210 \& FAX: 512-475-8744
}

The following paper is a pre-print, the final publication can be found in Transportation Research Part D, 43: 123-132, 2016.

\begin{abstract}
While the phenomenon of excess vehicle emissions from cold-start conditions is well known, the magnitude and duration of this phenomenon is often unclear due to the complex chemical processes involved and uncertainty in the literature on this subject. This paper synthesizes key findings regarding the influence of ambient and engine temperatures on light-duty vehicle (LDV) emissions. Existing literature, as well as analytical tools like the U.S. Environmental Protection Agency's Motor Vehicle Emission Simulator (MOVES), indicate that while total vehicle emissions have dropped significantly in recent years, those associated with cold starts can still constitute up to $80 \%$ for some pollutant species. Starting emissions are consistently found to make up a high proportion of total transportation-related methane $\left(\mathrm{CH}_{4}\right)$, nitrous oxide $\left(\mathrm{N}_{2} \mathrm{O}\right)$, and volatile organic compounds (VOCs). After three to four minutes of vehicle operation, both the engine coolant and the catalytic converter have generally warmed, and emissions are significantly lower. This effect lasts roughly 45 minutes after the engine is shut off, though the cooling rate depends greatly on the emission species and ambient temperature. Electrically (pre-)heated catalysts, using the bigger batteries available on hybrid drivetrains and plug-in vehicles, may be the most cost-effective technology to bring down a big share of mobile source emissions. Trip chaining (to keep engines warm) and shifting to non-motorized modes for shorter trips, where the cold start can dominate emissions, are also valuable tactics.
\end{abstract}

\section{INTRODUCTION}

Vehicle cold starts are an important source of major air pollutants, including uncombusted hydrocarbons (HC), carbon monoxide (CO), oxides of nitrogen (NOx), and particulate matter (PM). In the first minutes of engine operation, when engine block and coolant temperatures are low, incomplete combustion results in significantly higher emissions than at ordinary operating temperatures (Cao, 2007). This effect is magnified by the modern catalytic converter, which was adopted as a standard vehicle feature in order to control these three pollutants and improve air quality (CARB 2012). Each of these pollutant species carries potentially serious health and environmental costs. HC, for example, is part of a broader category known as volatile organic compounds (VOCs), which can cause headaches, nausea, and kidney and liver damage, and various VOCs are carcinogenic for humans (EPA, 2012). CO inhibits oxygen intake and can be fatal at large doses. Prolonged exposure to NOx can result in chronic bronchitis, asthma, and other respiratory problems. The mortality impacts of these pollutants can be in the tens of thousands of dollars per ton emitted, and depends in large part on how many humans are exposed (EPA, 2013). 
Due to serious air pollution, particularly in California's Los Angeles region, the U.S. Environmental Protection Agency (EPA) has been regulating the light-duty vehicle fleet's emissions of these substances since 1968, and began regulating PM with the 1994 model year. More recently, the EPA has also cut by around three-quarters the allowable sulfur content in gasoline for on-road use, and recent LEV III standards are expected to continue to decrease tailpipe emissions (EPA, 2014). While gasoline blends have gotten cleaner over the years, and catalytic converters do filter a substantial portion of primary pollutants (largely $\mathrm{CO}, \mathrm{NO}_{\mathrm{x}}$, and $\mathrm{HC}$, after reaching approximately $400^{\circ} \mathrm{F}$ ) (Reif, 2015), lower running emissions during engine operation mean that increased starting emissions make up a large and growing share of total vehicle emissions. In the case of PM, the catalytic converter does relatively little, but high vehicle operating temperatures are still key to low-emissions operation.

This paper quantifies the cold-start effect for U.S. light-duty fleet conditions. A literature review first summarizes key relationships between temperature and tailpipe and evaporative emissions. Next, the proportion of total light-duty vehicle emissions attributable to cold starts is calculated using the EPA's Motor Vehicle Emission Simulator (MOVES) (EPA, 2011). Finally, this paper highlights other relevant emissions considerations, such as evaporation and re-suspension, as well as various strategies for reducing cold-start emissions. Excess emissions attributable to cold starts vary widely by pollutant species, accounting for 10 to $30 \%$ of total mobile source emissions in most cases. For both fine and coarse PM, the proportion is about 10 to $20 \%$ of combined starting and running emissions. This does not reflect brake and tire dust or re-suspension, which are major sources of PM air pollution, as discussed toward the end of this paper.

\section{Defining Cold Starts}

An internal combustion engine's (ICE's) chemical processes are complex, making it difficult to pinpoint what constitutes a cold engine start in a way that is scientifically and practically meaningful. As the terminology "cold start" implies, the key factor is the difference in temperature from regular operating conditions (for both the engine and catalytic converter). A reasonable starting point is to ask, "At what temperatures do fuel consumption and emissions profiles become qualitatively different from those of a vehicle at steady operating temperature?”

The EPA (1993) defines a "hot start" as one during which both engine and catalytic converter are near operating temperatures. A hot start thus requires that the previous trip be at least four minutes long (two minutes to heat the catalyst and another two to reach at least $140^{\circ} \mathrm{F}$ coolant temperature, assuming a typical internal combustion engine) and the soak length be no more than 45 minutes, after which the catalytic converter has cooled considerably (EPA, 1993). Catalytic converters require extremely high temperatures to operate at intended efficiency (Reif, 2015), so they drop below their optimal temperatures much more quickly than the engines.

A "warm start" occurs when the engine is still hot but the catalytic converter is cool, and a cold start occurs when both engine and catalytic converter have cooled to within 10 degrees Fahrenheit of the ambient temperature (EPA, 1993). The EPA also defines a cold start in terms of time passed since engine operation: it is any start that occurs at least one hour after the end of the preceding trip for catalystequipped vehicles (EPA, 1994), which covers the vast majority of the current vehicle fleet since the EPA has required catalytic converters on nearly all light-duty vehicles built since 1975.

These cold-, warm-, and hot-start definitions mask considerable variation between vehicles, across starting ambient temperatures, and after different soak lengths (engine-off times). In truth, many definitions of a cold start, including in official documents, are vague. For example, the EPA (1993) also considers a start "cold" "if it is preceded by a long uninterrupted soak, such as those starts that occur after an overnight soak". U.S. law (CFR 2013) requires a soak time between 12 and 36 hours prior to testing 
for cold-start emissions. These regulations also specify that "a set of cold start criteria based solely on ambient temperature exceeding engine coolant temperature will not be acceptable.” Fortunately, there are several methods for quantifying cold start emissions more specifically, in the lab and using publicly available tools and data sets.

\section{QUANTIFYING COLD START EMISSIONS}

The most accurate way to measure the magnitude of vehicle emissions in general, and those attributable to cold starts in particular, is through repeated testing of vehicles under real-world driving conditions using sophisticated sensing technology. Unfortunately, this is expensive and time-consuming, and existing research tends to focus on a single pollutant or a small sample of vehicles (e.g., Robinson et al. [2010], Lee et al. [2012], Kleeman et al. [2000]). Nevertheless, this study builds on prior laboratory work and clarifies our current understanding by first summarizing the relevant literature on cold starts.

Relevant parameters, as well as specific emissions rates, were sought for all criteria pollutants, with emphasis on $\mathrm{PM}$ and $\mathrm{SO}_{2}$, due to these species' disproportionate health and environmental costs.

The synthesis of existing work is augmented by emissions estimates developed using EPA's MOVES model. MOVES is a powerful tool for anticipating emissions based on a variety of parameters, including time of day, month of the year, pollutant species, and emissions process. Unlike previous programs, such as VT-MICRO and CMEM, MOVES explicitly models starting emissions separately from running emissions (Fujita et al., 2012). A single weekday in many US metropolitan areas represents millions of vehicle-miles traveled (VMT) across a variety of roadway types, speed profiles, and vehicle attributes, and thus a large city's or region's total mobile-source emissions are substantial.

In this study, default MOVES data were used to develop county-wide emissions inventories for regulated pollutants, air toxics, and greenhouse gases (as $\mathrm{CO}_{2}$ and $\mathrm{CO}_{2} \mathrm{eq}$ ). Comparisons of running versus starting emissions quantify the relative importance of vehicle cold starts with regard to each pollutant species. Base estimates come from a single scenario: a weekday in July 2010 in Travis County, Texas (which contains the City of Austin).

The simulation was then expanded to encompass the month of January, and other years (ranging from year 2000 to 2025), in order to reveal seasonal and longer-term variations in emissions levels - and the relative importance of cold start conditions, due to changes in fuel composition and vehicle technologies. Finally, emissions were simulated for other counties, around the U.S., to appreciate regional variations.

\section{Existing Estimates of Cold Start Emissions}

Measuring cold-start emissions changes due to temperature variation and other factors presents a significant challenge. It can take up to 12 hours to fully cool an engine to steady state, but heat loss is most significant in the first two hours after shutdown. Start-up emissions produced after the engine has been off for even 15 minutes can be high. According to the EPA (2011), a hot start after a soak period of three minutes results in average increases of less than $10 \%$ in CO, HC, and NOx emissions, per mile traveled (as compared to hot running levels). After just 45 minutes, the catalytic converter has cooled significantly, and CO and HC are halfway back to cold-start levels, while NOx has recovered more than $85 \%$ of the difference.

This raises a key question: How long are engines off? The EPA (1993) found that almost $40 \%$ of realworld soak times in Baltimore, Maryland lay between 10 minutes and two hours. Similar findings come from the more recent Commute Atlanta study (Guensler et al., 2007), with 16.1\% of the Georgia region's soak times lying within the 0 to 5 minute interval and 17.9\% lying between 8 and 24 hours (the two most common bins). Intermediate soak lengths, between 5 minutes and two hours duration, accounted for over 43\% of Atlanta’s LDV starts (Guensler et al., 2007). 
Some emissions come simply from starting the engine. For example, Gaines et al. (2013) found that a hot start emits more HC than ten minutes of idling, and more CO than idling the engine for 45 minutes and longer. André and Joumard (2005) estimated a broad distribution (by species) for what they call "cold start distances," with an average of $5.2 \mathrm{~km}(3.2 \mathrm{miles})$ at $20^{\circ} \mathrm{C}\left(68^{\circ} \mathrm{F}\right)$. In other words, it may take 3.2 miles of driving before emissions rates of some pollutants stabilize when ambient temperature is $68^{\circ} \mathrm{F}$.

This is particularly important in densely developed settings, because many automobile trips are short in distance and duration, so a significant share of urban driving takes place while the engine is cold - and human exposure (in denser settings) is relatively high. Research in Europe suggests cold start emissions may comprise as much as 50\% of urban driving emissions (Sérié and Joumard, 1998). The U.S. 1995 Nationwide Personal Transportation Survey revealed that nearly half of all person-trips were three miles or less (de Nazelle et al., 2010). And the median LDV trip distance in the 2009 NHTS is just 4.0 miles, with $43.4 \%$ of all personal-vehicle trips being less than 3.2 miles in length (USDOT, 2010). At these relatively short distances, most pollutant species would not have stabilized at low, hot-running levels before the engine is turned off and begins cooling again. All this suggests that cold starts deserve special attention by travelers and policymakers, especially in regions and neighborhoods where most vehicle-trips are relatively short (and engines cold).

However, these results vary across studies. Surveying a representative sample of late-model vehicles from the Swiss fleet at $25^{\circ} \mathrm{C}\left(77^{\circ} \mathrm{F}\right)$ and $28 \mathrm{~km} / \mathrm{h}(17 \mathrm{mph})$, Favez et al. (2009) estimated an average "cold distance" of just $1 \mathrm{~km}$ (0.6 miles), with a maximum of $3 \mathrm{~km}$ (1.9 miles). Chen et al. (2011) reported a 120 -second cold start duration (which is typically 1 mile or less of travel distance on local streets, where most trips begin), and noted that gasoline blended with 20-30\% ethanol can lower HC, CO, and NOx emissions during cold starts.

Defining cold start in terms of associated PM emissions and PM size distribution, Robinson et al. (2010) measured cold start times between 165 and 230 seconds using a 1999 Toyota Sienna minivan at temperatures ranging from $68^{\circ} \mathrm{F}$ to $99^{\circ} \mathrm{F}$ (i.e., $20^{\circ} \mathrm{C}$ to $37^{\circ} \mathrm{C}$ ). In this case, times reflect primarily those required to heat the engine, since the catalytic converter has little effect on PM emissions. The cold start durations in this study suggest "cold distances" of 2 miles or less, given operating speeds at the start of most vehicle trips.

In terms of specific emission species, Lee et al. (2012) produced estimates using a specially equipped 1999 Dodge Grand Caravan SUV. By comparing the emissions bagged during the first and third phases of the U.S. federal test procedure (FTP) for vehicle emissions (which are identical except for the engine temperature at the beginning of the phase), they estimated that a cold engine emits $3.46 \mathrm{gm} / \mathrm{mi}$ (gpm) of $\mathrm{CO}$, or nearly three times what a warm engine produces. The cold engine was also responsible for 0.79 gpm of NOx and $0.48 \mathrm{gpm}$ of total hydrocarbons (THCs). These values are nearly double and nearly quadruple the respective rates for the warmed/hot engine in their test chamber (Lee et al., 2012). They also found minimal PM (as PM10 and PM2.5) emissions, under the detection threshold for most driving cycles, and so concluded that MOVES' PM estimates may be biased high. On the other hand, Nam et al. (2008) estimated that approximately 30\% of total vehicle PM emissions occur during cold start, and found that Phase 1 (cold-start) emissions were 7.5 times those of Phase 3. Kleeman et al. (2000) noted that PM size distribution varied little between their samples of the cold and hot start portions of the FTP driving cycle.

Diesel combustion is relatively fuel-efficient, especially for heavy-duty applications. For the same engine load, diesel engines emit less $\mathrm{CO}, \mathrm{HC}$, and $\mathrm{CO}_{2}$ than gasoline-fuelled engines, but emit much more PM. Conventional port fuel injection (PFI) gasoline engines emit at least 90 percent less PM than diesel engines, per mile of travel, which is why until recently there has been little regulation of PM in gasoline engines. Newer gasoline direct injection (GDI) technologies offer better fuel economy and increased 
power, but emit significantly more PM than PFI vehicles (Myung and Park, 2012) - perhaps on the order of $14 \mathrm{mg} / \mathrm{mi}$ during the first 505 seconds of the FTP (Zhang and McMahon, 2012), as compared to Lee et al.'s (2012) estimate of just $1 \mathrm{mg} / \mathrm{mi}$ with an older, PFI vehicle.

These experimental results are useful, but many of them focus on a small sample of vehicles at a constant, moderate ambient temperature. What about the big picture of vehicle emissions across an entire metropolitan area? The following section considers an alternative approach to quantifying cold start emissions using a simulation tool developed by the U.S. Environmental Protection Agency.

\section{MOVES Estimates of Cold Start Emissions}

The default database built into MOVES, aggregated at the county level, provides a sense of the proportion of emissions species that result from cold starts, rather than from the more common "hot running" of engines. Figure 1 shows the percentage of total running and starting emissions (which include evaporative emissions during engine operation, but not brake or tire-wear emissions) that are due to vehicle starts, as estimated for a typical weekday in July 2010 in Austin, Texas’ Travis County. Clearly, methane $\left(\mathrm{CH}_{4}\right)$ and other $\mathrm{HCs}$ (which overlap most VOC species) and $\mathrm{NO}_{2}$ are strongly affected by starting conditions. Catalytic converters are designed to reduce CO and NOx, though MOVES' CO estimates do not suggest that converters are appreciably more effective at reducing CO and NOx than they are at reducing PM (which is removed by a heated engine, thanks to more complete combustion). Since $\mathrm{CH}_{4}$, $\mathrm{HC}$ (as VOC) and $\mathrm{N}_{2} \mathrm{O}$ appear as dominant species in cold-start emissions, these three species are the focus of much of the rest of this paper. $\mathrm{CO}$ is also included because it is among the primary pollutants regulated by the EPA since 1968, along with HC and NOx. Methane is not currently regulated from mobile sources, but is a powerful greenhouse gas. In addition, short-term exposure to concentrations of $15 \%$ can cause dizziness and headaches (Wisconsin DHS, 2012).

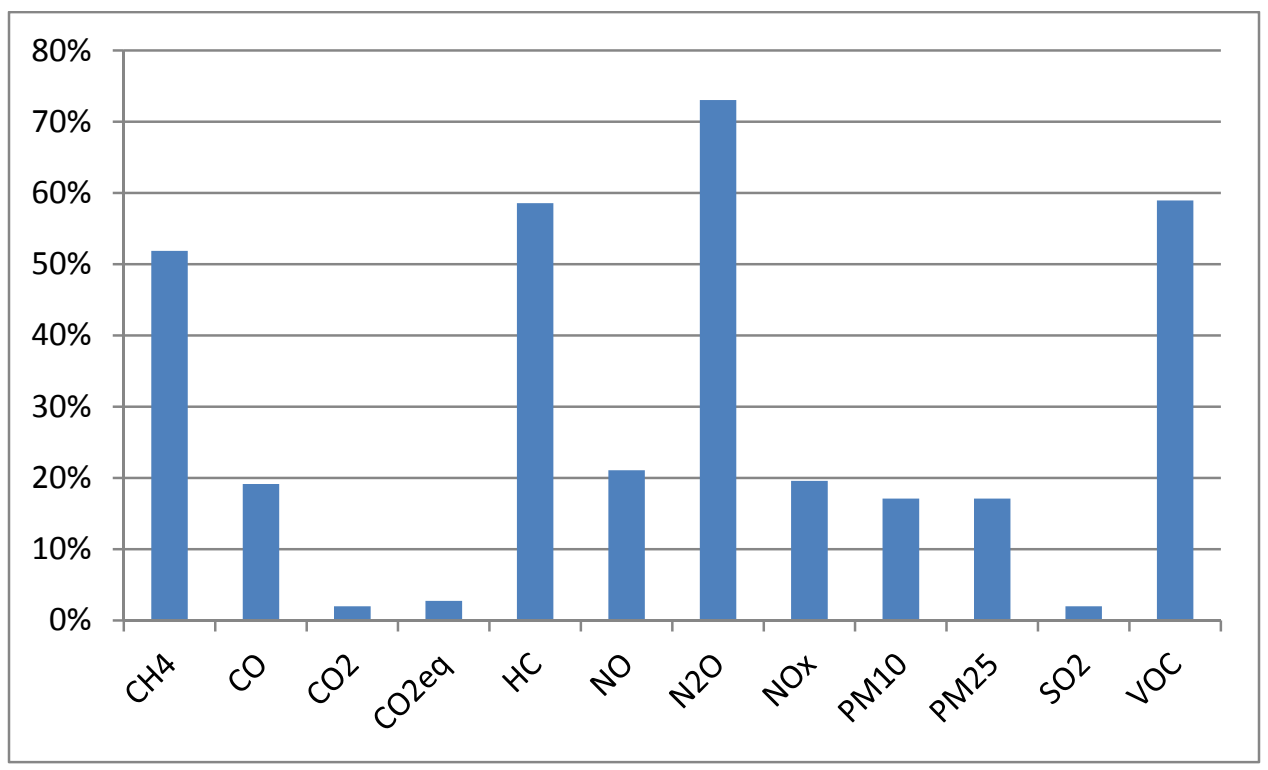

FIGURE 1 Percentage of running and starting emissions attributable to starts (MOVES output). Travis County, Texas, July 2010 weekday, LDVs only

\section{Ambient Temperature Effects}

Temperature affects vehicle emissions in at least two opposing ways: lower ambient temperatures raise cold-start emissions for most pollutant species, while higher engine or ambient temperatures increase evaporative emissions of gasoline (which are included in MOVES' running emissions while the engine is running, but continue throughout the day, especially in hot weather). This is illustrated in Figure 2, which shows cold start emissions shares falling substantially during summer months. This is partly due to 
summer starts resulting in lower absolute emissions, and partly because of increased evaporative and running emissions in hotter weather.

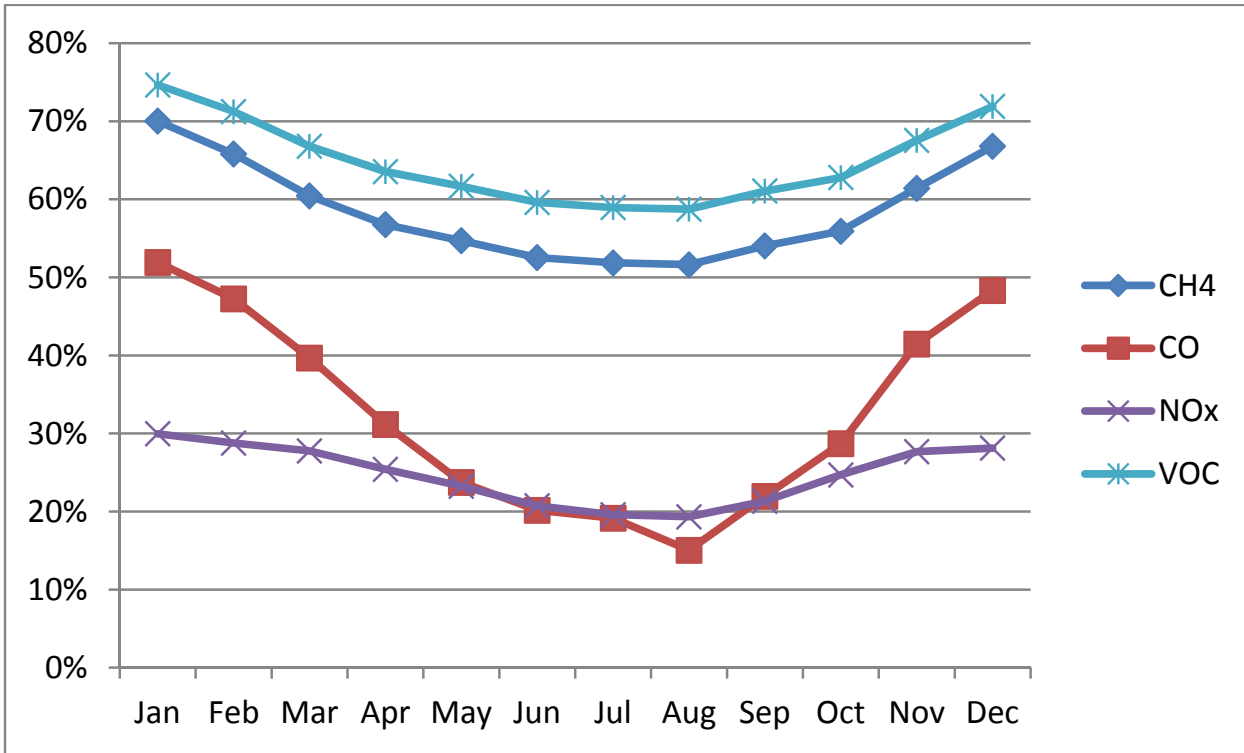

FIGURE 2 Percentage of key running and starting emissions attributable to cold starts over months of the year (MOVES output). Travis County, Texas, 2010 weekday, LDVs only

The technologies being used for significant reductions in overall vehicle emissions over the last four decades have resulted in dramatic cold-weather effects: modern gasoline vehicles now emit about 15 times more $\mathrm{CO}$ and 35 times more $\mathrm{HC}$ when started at $-4^{\circ} \mathrm{F}$ as compared with $73^{\circ} \mathrm{F}$ (i.e., $-20^{\circ} \mathrm{C}$ to $+23^{\circ} \mathrm{C}$ ) (Weilenmann et al., 2009). Only $\mathrm{CO}_{2}$ (the primary greenhouse gas of anthropogenic origin) does not show a strong inverse relationship with ambient temperature (Sentoff et al., 2010).

In Robinson et al.'s (2010) measurements of cold start times, they found that lower ambient temperatures did not increase starting PM emissions rates per minute or per mile, but resulted in longer times to warm the engine, which generated higher total PM emissions. Nam et al. (2010) found that cold-start per-mile $\mathrm{PM}$ emissions approximately doubled for every $20^{\circ} \mathrm{F}$ drop in ambient temperature. In terms of other species, Weilenmann et al. (2005) found that cold ambient temperatures have a "disproportional" effect on HC emissions, a moderate impact on CO, and little to no effect on NOx emissions, which are relatively low (as a share of total emissions, as shown in Figure 1) and essentially constant. Figure 3 summarizes those results.

Such numbers are important because many real-world conditions fall outside formal test procedures' prescribed temperature intervals. For example, Lejon et al. (2010) note that European emissions tests generally call for an ambient temperature between 68 and $86^{\circ} \mathrm{F}$, even though the average annual temperature across the continent is closer to $50^{\circ} \mathrm{F}$, and in northern EU countries the average lies below $41^{\circ} \mathrm{F}$. Fortunately, Dardiotis et al. (2013) recently found that, despite cold start emissions being 2 to 11 times higher at $19^{\circ} \mathrm{F}$ than at $72^{\circ} \mathrm{F}$, modern gasoline engines emit substantially less than current legislation requires, even at the colder temperature.

\section{Geographic Variability}

Travis County, Texas provides an interesting test case, but does not necessarily represent the reality of other metropolitan areas. Figure 3 shows cold start emissions of methane, CO, NOx, and VOCs for several other counties across different regions of the country. With one exception (Dane County, 
Wisconsin, which contains the city of Madison), cold start shares are relatively consistent across regions. Cold-start emissions shares during January are almost uniformly higher than those during July.

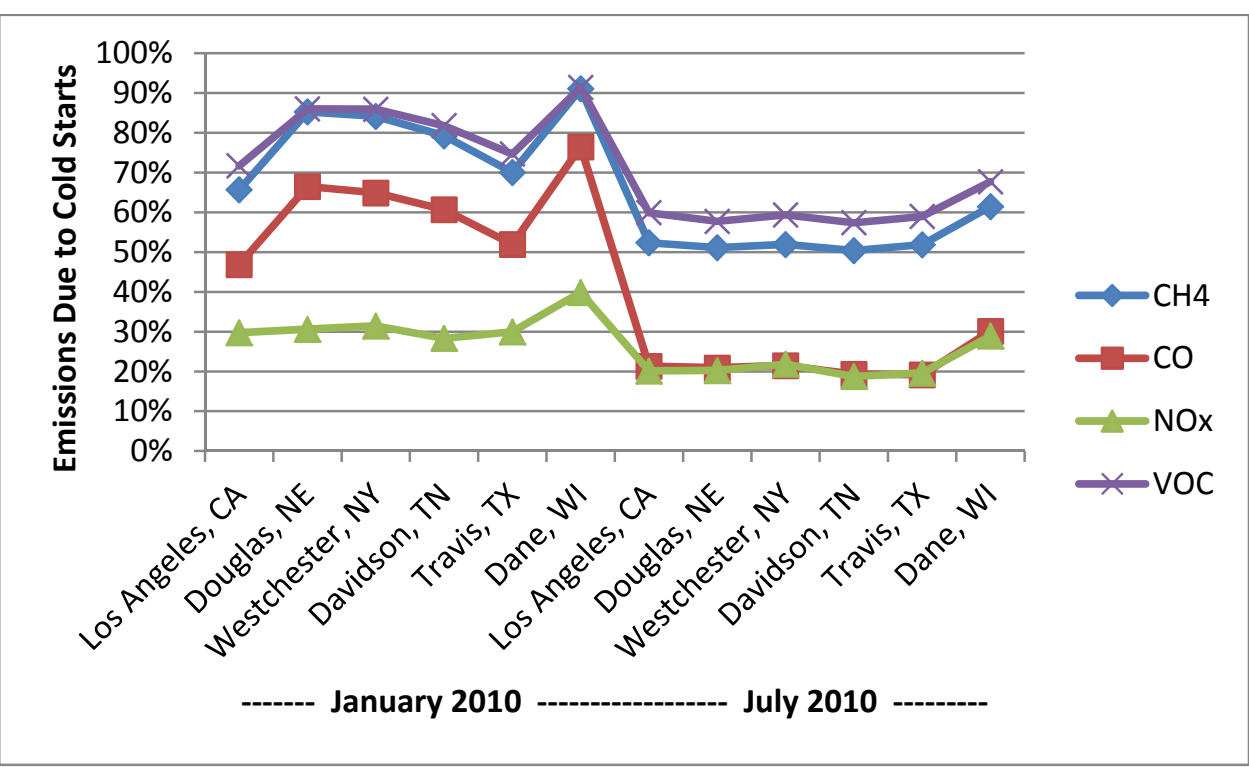

FIGURE 3 Cold start emissions shares across U.S. regions (MOVES output), 2010 weekdays, LDVs only

\section{Evolution over Time}

Figure 4 illustrates the evolution of cold-start LDV emissions across years, with winter versus summer season variations, for Travis County. As expected, each of the four species exhibits a higher cold start share in winter due to lower ambient temperatures. The MOVES model forecasts cold-start shares to rise over time, reaching 80 to 90 percent in the case of VOCs in year 2025. Fortunately, this sharp increase in shares is due to significant reductions in running emission rates. In fact, the U.S. expects significant continuing reductions in both starting and running emissions across its LDV fleet, which should translate to lower overall emissions in Travis County as well. For example, Travis County's mobile-source emissions of NOx and VOC are expected to fall 93 and 95 percent, respectively, between 2000 and 2025, while VMT is expected to rise 45 percent. 


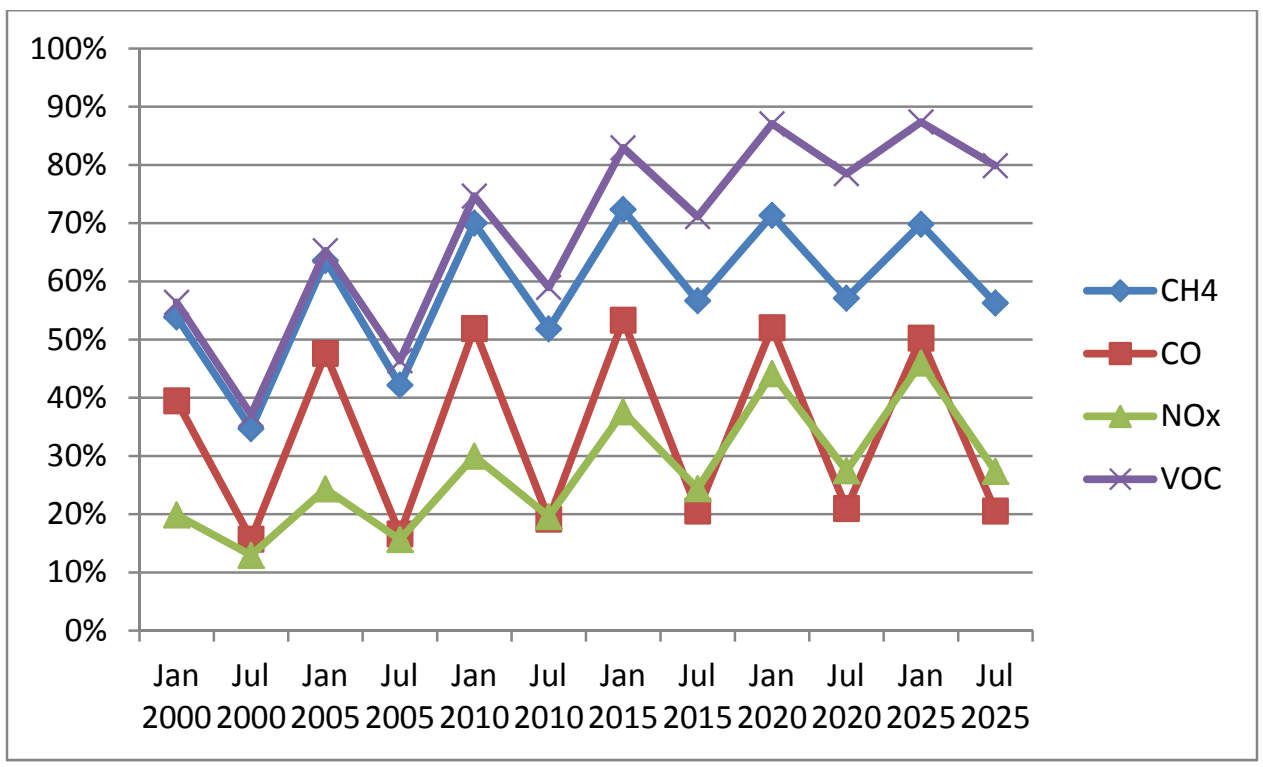

FIGURE 4 Evolution of Travis County weekday cold start emissions proportions, 2000-2025

Figures 5 and 6 depict this evolution over time by comparing normalized running plus starting emissions totals from 2000 through 2025 at 5-year intervals. Anticipated mobile-source emissions from LDVs drop dramatically on each of these species over time, despite a 40 to 50 percent increase in total VMT over the 25-year period considered.

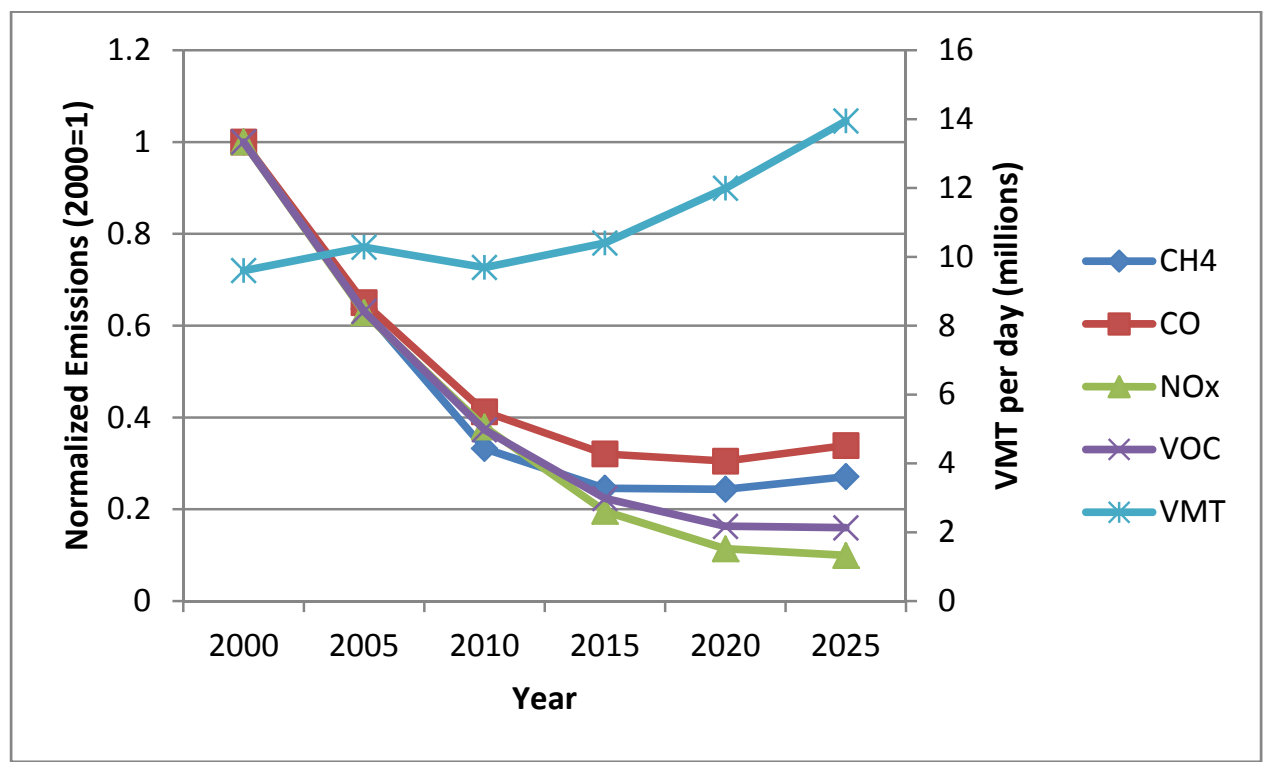

FIGURE 5 Normalized running plus starting LDV emissions totals over time (MOVES output), January weekday, Travis County, Texas $(y=1.0$ serves as reference for year 2000) 


\section{FIGURE 6 Normalized running plus starting LDV emissions over time (MOVES output), July weekday, Travis County, Texas ( $y=1.0$ serves as reference for year 2000)}

\section{Strategies for Reducing Cold Start Emissions}

Several strategies exist for reducing cold-start emissions. For example, since starting emissions shares are most significant on shorter trips, de Nazelle et al. (2010) considered the environmental benefits of shifting to alternative modes, like biking and walking, for journeys less than 3 miles in distance. They found that the associated emissions reductions exceeded those associated with many projects funded by the federal Congestion Mitigation and Air Quality (CMAQ) Improvement Program, including natural gas buses, hybrid fleet vehicles, and tolled freeway lanes.

Other changes can also prove very valuable. For example, a fleet shift toward hybrid electric vehicles can delay need for and use of a catalytic converter until it is pre-heated. Fully electric vehicles may shift travel-related emissions to remote power-generating units or even ultimately derive their power from clean renewable feedstocks (Nichols et al., 2014). Systems of shared autonomous vehicles may also reduce the incidence of cold starts by avoiding engine cool-down periods, and thus yield significant emissions savings (Fagnant and Kockelman, 2014).

Along with these potential mode shifts and vehicle-type shifts, the key is to warm the catalytic converter as quickly as possible, reducing the level of cold-start emissions in conventional vehicles. While many drivers may assume it is best to idle the engine for a time before driving the vehicle, initial idling is only advisable in extreme cold in order to prevent engine damage. In milder weather, idling contributes to higher emissions than warm-up driving, and does not heat the emissions control equipment as quickly as driving (even slowly) for the first few minutes (Sentoff et al., 2010).

Since the operating temperature of the catalytic converter is crucial, one simple idea is to relocate the converter closer to the engine, so that it will warm up more quickly. This has proven an effective strategy in reducing emissions, but in the past has introduced unwanted heat into the passenger compartment (Burch et al., 1995). More recently, exhaust temperatures have dropped and the catalyst has been placed closer to the engine (Presti and Pace, 2011).

Catalytic converter technologies also continue to improve. For example, Nissan has developed a hydrocarbon trap, using an innovative blend of silver and zeolite, which significantly reduces tailpipe emissions by trapping some of the elevated hydrocarbons emitted by a cold engine (Hamada, 2009). As 
this technology matures, it may become a standard feature of new vehicles, while adding relatively little to the purchase price. Alternatively, car companies have long experimented with battery-powered preheaters, but concerns about energy efficiency and equipment durability have prevented widespread adoption. Recent improvements in battery technology have helped to make this a feasible option with little additional fuel consumption, especially in hybrid electric vehicles (Presti and Pace, 2011).

One particularly promising idea is the use of innovative thermal materials in the catalytic converter to retain heat longer and reduce the rate of engine cooling. National Renewable Energy Laboratory tests showed that a prototype maintained high converter temperatures for 17 hours, as compared to 25 minutes for conventional converters (Burch et al., 1995). A more recent study, using a phase-change heat storage material, obtained reductions of $64 \%$ for $\mathrm{CO}$ and $15 \%$ for HC after a 500 -second pre-warming period (Gumus, 2009). This pre-warming involved the discharge of stored heat from the heat storage medium, and did not require engine idling, so the catalyst's improved performance came without idling's added emissions and engine wear.

This novel use of materials may eventually prove unnecessary, as computers are integrated into every aspect of engine operation. Computerized fuel injection already helps optimize gas mileage and may also be used in the future to minimize emissions in the minutes following a cold start (Spiegel, 2014).

\section{OTHER CONSIDERATIONS Evaporative Emissions}

Another major source of vehicle emissions is evaporation of unburned gasoline from parked vehicles. This is particularly a problem during summer months, when ambient temperatures can exceed $100^{\circ} \mathrm{F}$ and engine components remain at an elevated temperature much longer than in the winter. It is estimated, for instance, that $19 \%$ of gasoline VOC emissions in the UK are due to evaporation (Boulter et al., 2009). The EPA estimates that a typical 2002 model car emits 4.3 grams per day of VOC, simply sitting parked, which is more that $10 \%$ of total average weekday emissions for this species. An approximately equal proportion can be attributed to the "hot soak" period, when the vehicle is off but its engine is still hot (EPA, 2004). This is the rationale behind testing gas tank caps during mandatory vehicle emissions inspections in many jurisdictions (e.g., Texas DPS [2011] and Fischer [2014]).

\section{Additional Sources of Particulate Matter}

While PM10 and PM2.5 emissions from internal combustion engines are a cause for concern, vehicle brake wear typically generates more PM10, on average, even during winter months, as shown in Figure 7. Tire wear and tear is also important to track, contributing more PM10 than starting emissions. Such contributions to total PM pollution are significant, and are relatively unaffected by changes in engine technology. Tires may experience less wear if (unless, for example, battery-powered vehicles accelerate more intelligently than conventionally designed and driven vehiclesvia use of significantly lower weightsuch). Interestingly, in the warmer months of summer, when more efficient engine processes cause both starting and running PM emissions to decline, brake and tire-related PM actually increase. 


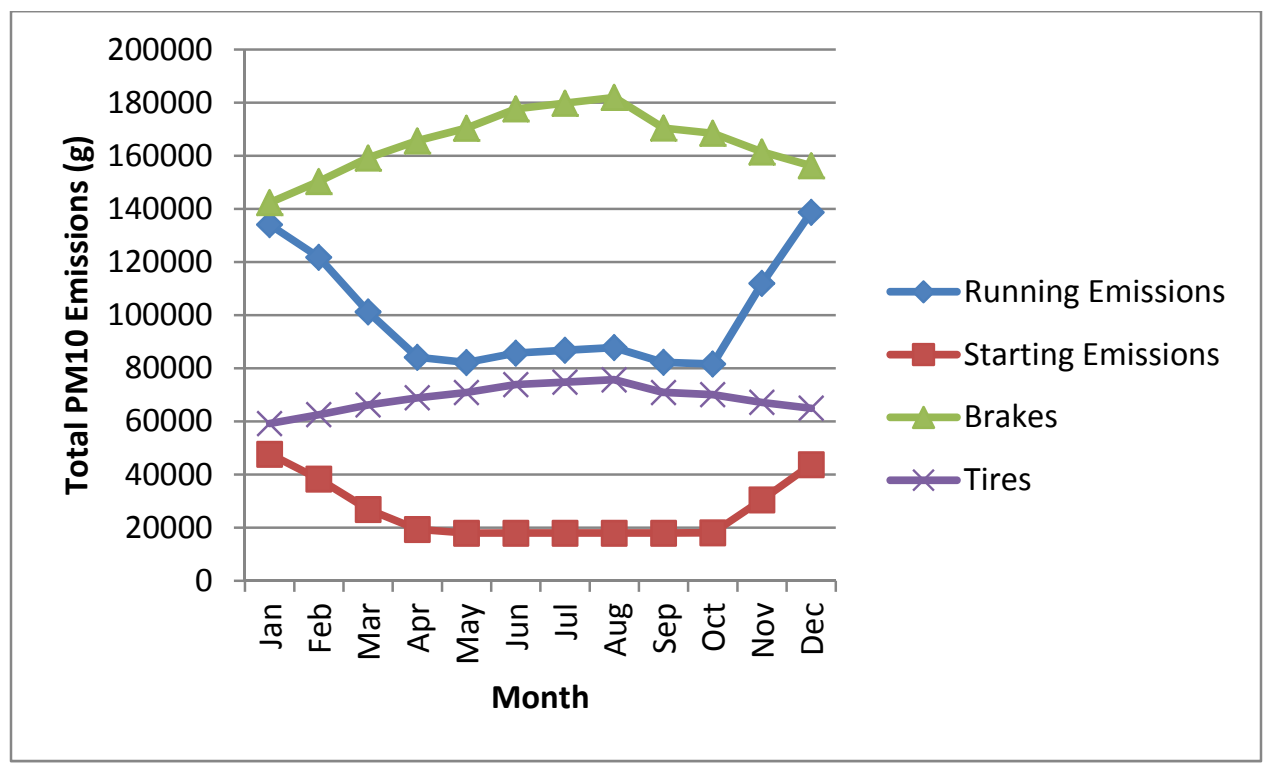

\section{FIGURE 7 Total grams of PM10 from light-duty gasoline vehicles in Travis County, Texas (MOVES output) 2010 weekdays, LDVs only}

PM is also susceptible to re-suspension. After such matter has finally settled onto the road surface, it may be lofted into the atmosphere again via air turbulence caused by passing vehicles (Boulter et al., 2009). This source of PM pollution is especially important for human exposure and thus human health, since it keeps particles at low altitudes, within range of the human respiratory system, with potentially serious consequences.

To summarize, while engine and converter temperatures are key to cold start emissions of ICEs, and cold start emissions are a significant share of mobile source emissions, many other considerations are at play. Month to month temperature variations, trends in vehicle technologies and regulations, other types of emissions (e.g., evaporative and re-suspended PM), and a variety of emissions-abating strategies merit attention.

\section{CONCLUSIONS}

This paper synthesizes a variety of current knowledge about cold start emissions for motor vehicles. Simulations performed using EPA's MOVES program suggests that, regardless of geographic location or time of year, $\mathrm{CH}_{4}, \mathrm{~N}_{2} \mathrm{O}$, and VOC constitute a significant cost of cold engine starts. Looking toward the future, the same top pollutants continue to appear, but absolute levels of emissions decline substantially. Other potential sources of vehicle power, such as electricity, are undergoing their own sharp reductions in pollutant emissions. This could have major implications for the future of transportation.

Going forward, a key policy question is: which approach is most promising for emissions-related health and environmental benefits? With the relatively recent introduction of hybrid electric vehicles, battery technology has advanced dramatically. These new battery packs have sufficient power to pre-heat the catalytic converter, thereby resolving the difficulties of either relocating the cat or searching for a suitable heat-storage medium (which typically stores heat for 10 to 20 hours after vehicle shutoff, and so does not resolve all cold-start emissions incidents).

\section{ACKNOWLEDGEMENTS}

The authors appreciate the National Science Foundation's support of the first author's time on a Research Experience for Undergraduates (REU), via the EV-TEC Industry-University Research Center. They also 
wish to thank John German for his vehicle emissions expertise, Dr. Scott Fincher for assistance with MOVES, and Annette Perrone for her administrative support.

\section{REFERENCES}

André, J. and R. Joumard (2005). Modelling of Cold Start Excess Emissions for Passenger Cars. INRETS Report LTE 0509.

Boulter, P., T. Barlow, I. McCrae, and S. Latham (2009). Emission Factors 2009: Final Summary Report. Published Project Report PPR 361.

Burch, S., T. Potter, M. Keyser, M. Brady, and K. Michaels (1995). Reducing Cold-Start Emissions by Catalytic Converter Thermal Management. NREL/TP-473-7025. National Renewable Energy Laboratory.

CARB (2012). Key Events in the History of Air Quality in California. California Air Resources Board. http://www.arb.ca.gov/html/brochure/history.htm

Cao, Y. (2007). Operation and Cold Start Mechanisms of Internal Combustion Engines with Alternative Fuels. SAE Technical Paper 2007-01-3609, doi:10.4271/2007-01-3609

Chen, R., L. Chiang, C. Chen, and T. Lin (2011). Cold-Start Emissions of an SI Engine Using EthanolGasoline Blended Fuel. Applied Thermal Engineering 31 (8): 1463-1467.

Code of Federal Regulations (2013). Control of Emissions from New and In-Use Highway Vehicles and Engines. 40 CFR 86.

Dardiotis, C., G. Martini, A. Marotta, and U. Manfredi (2013). Low-Temperature Cold-Start Gaseous Emissions of Late Technology Passenger Cars. Applied Energy 111: 468-478.

de Nazelle, A., B. Morton, M. Jerrett, and D. Crawford-Brown (2010). Short Trips: An Opportunity for Reducing Mobile-Source Emissions? Transportation Research Part D 15 (8): 451-457.

EPA (1993). Federal Test Procedure Review Project: Preliminary Technical Report. U.S. Environmental Protection Agency report: EPA 420-R-93-007.

EPA (1994). User’s Guide to Mobile5 (Mobile Source Emission Factor Model). U.S. Environmental Protection Agency report: EPA-AA-AQAB-94-01.

EPA (2004). MOBILE6.2 Model run assumed IDLE Test, National Low Emission Vehicle Standards, summer temperature 64-92 degrees, and United States average vehicle operations. Cited at https://www.fhwa.dot.gov/environment/air_quality/publications/fact_book/page15.cfm.

EPA (2011). Development of Emission Rates for Light-Duty Vehicles in the Motor Vehicle Emissions Simulator (MOVES2010). U.S. Environmental Protection Agency report: EPA-420-R-11-011 http://www.epa.gov/otaq/models/moves/documents/420r11011.pdf

EPA (2012). An Introduction to Indoor Air Quality. U.S. Environmental Protection Agency, Washington D.C. http://www.epa.gov/iaq/ia-intro.html

EPA (2013). Technical Support Document: Estimating the Benefit per Ton of Reducing $\mathrm{PM}_{2.5}$ Precursors from 17 Sectors. http://www.epa.gov/airquality/benmap/models/Source_Apportionment_BPT_TSD_1_31_13.pdf

EPA (2014). EPA Sets Tier 3 Motor Vehicle Emissions and Fuel Standards. http://www.epa.gov/otaq/documents/tier3/420f14009.pdfFagnant, D. and K. Kockelman (2014). The Travel and Environmental Implications of Shared Autonomous Vehicles, Using Agent-Based Model Scenarios. Transportation Research Part C, 40: 1-13. 
Favez, J., M. Weilenmann, and J. Stilli (2009). Cold Start Extra Emissions as a Function of Engine Stop Time: Evolution over the Last 10 Years. Atmospheric Environment 43: 996-1007.

Fischer, H. (2014). Failed emissions test? Try a free gas cap. Arizona Daily Star http://tucson.com/news/state-and-regional/failed-emissions-test-try-a-free-gas-cap/article_35dad1e99037-5a85-a7a2-a1d21006eb6c.html

Fujita, E., D. Campbell, B. Zielinska, J. Chow, C. Lindhjem, A. DenBleyker, G. Bishop, B. Schuchmann, D. Stedman and D. Lawson (2012). Comparison of the MOVES2010a, MOBILE6.2, and EMFAC2007 mobile source emission models with on-road traffic tunnel and remote sensing measurements. Journal of the Air \& Waste Management Association 62 (10): 1134-1149.

Gaines, L., E. Rask, and G. Keller (2013). Which is Greener: Idle, or Stop and Restart? Compendium of papers presented at the Transportation Research Board's 92 ${ }^{\text {nd }}$ Annual Meeting.

Gao, H. and L. Johnson (2009). Methods of Analysis for Vehicle Soak Time Data. Transportation Research Part A 43 (8): 744-754.

Guensler, R., S. Yoon, H. Li, and V. Elango (2007). Atlanta Commute Vehicle Soak and Start Distributions and Engine Starts per Day: Impact on Mobile Source Emission Rates. United States Environmental Protection Agency. EPA/600/R-07/075

Gumus, M. (2009). Reducing cold-start emission from internal combustion engines by means of thermal energy storage system. Applied Thermal Engineering 29(4): 652-660.

Hamada, H. (2009). Novel Catalytic Technologies for Car Emission Reduction. OECD Conference on Potential Environmental Benefits of Nanotechnology.

http://www.oecd.org/science/nanosafety/44022244.pdf

Kleeman, M., J. Schauer, and G. Cass (2000). Size and Composition Distribution of Fine Particulate Matter Emitted from Motor Vehicles. Environmental Science and Technology 34 (7).

Kockelman, K., D. Fagnant, B. Nichols, and S. Boyles (2012). A Project Evaluation Toolkit for Abstracted Networks: Final Report. FHWA/TX-2013/0-6487-1. Center for Transportation Research, University of Texas at Austin. Available at http://www.utexas.edu/research/ctr/pdf_reports/0_6487_1.pdf.

Lee, D., J. Johnson, J. Lv, K. Novak, and J. Zietsman (2012). Comparisons Between Vehicular Emissions from Real-World In-Use Testing and EPA MOVES Estimation. Texas Transportation Institute, College Station, TX. (http://ntl.bts.gov/lib/46000/46400/46425/476660-00021-1.pdf)

Lejon, S., A. Svärd, L. Sandström-Dahl, and J. Tuominen (2010). Automotive Emissions from a Nordic Perspective: Literature Review. A Report for the Swedish Road Administration.

http://fudinfo.trafikverket.se/fudinfoexternwebb/Publikationer/Publikationer_001301_001400/Publikation _001385/Automotive\%20emissions\%20from\%20a\%20Nordic\%20perspective3.pdf

Myung, C. L. and S. Park (2012). Exhaust Nanoparticle Emissions from Internal Combustion Engines: A Review. International Journal of Automotive Technology 13 (1): 9-22.

Nair, H., C. Bhat, and R. Kelly (2001). Modeling Soak-Time Distribution of Trips for Mobile Source Emissions Forecasting: Techniques and Applications. Transportation Research Record 1750: 24-31.

Nam, E., C. Fulper, J. Warila, J. Somers, H. Michaels, R. Baldauf, R. Rydowski, and C. Scarbro (2008). Analysis of Particulate Matter Emissions from Light-Duty Gasoline Vehicles in Kansas City. United States Environmental Protection Agency. EPA-420-R-08-010 (http://www.epa.gov/otaq/emissionfactors-research/420r08010.pdf)

Nam, E., S. Kishan, R. Baldaul, C. Fulper, M Sabisch, and J. Warila (2010). Temperature Effects on Particulate Matter Emissions from Light-Duty, Gasoline-Powered Motor Vehicles. Environmental Science and Technology 44 (12): 4672-4677. 
Nichols, B., K. Kockelman, and M. Reiter (2014). Air Quality Impacts of Electric Vehicle Adoption in Texas. Forthcoming in Transportation Research Part D

501 (http://www.ce.utexas.edu/prof/kockelman/public html/TRB15EVEmissionsinTX.pdf).

502 Presti, M. and L. Pace (2011). An Alternative Way to Reduce Fuel Consumption During Cold Start: The 503 Electrically Heated Catalyst.

504 (http://www.emitec.com/fileadmin/user_upload/Bibliothek/Vortraege/11ICE_0255_Final_Manuel_Presti. 505 pdf)

506 Reif, K., ed. (2015). Gasoline Engine Management: Systems and Components. Available at 507 http://link.springer.com/chapter/10.1007/978-3-658-03964-6_18

508 Robinson, M., K. Sentoff, and B. Holmén (2010). Particle Number and Size Distribution of Emissions 509 During Light-Duty Vehicle Cold Start: Data from the Total Onboard Tailpipe Emissions Measurement 510 System. Transportation Research Record 2158: 86-94.

511 Sentoff , K., M. Robinson, and B. Holmén (2010). Second-by-Second Characterization of Cold-Start Gas512 Phase and Air Toxic Emissions from a Light-Duty Vehicle. Transportation Research Record 2158: 95513104.

514 Sérié, E. and R. Joumard (1998). Modelling of pollutant emissions during cold start for road vehicles. 515 International Journal of Vehicle Design 20 (1): 172-180.

516 Spiegel, A. (2014). Method for Reducing Engine Cold Start Emissions from Transient Fueling in an 517 Alternative Fueled Engine. Undergraduate Honors Thesis, Department of Mechanical Engineering, The 518 Ohio State University.

519 https://kb.osu.edu/dspace/bitstream/handle/1811/54507/FinalThesis.pdf?sequence=1

520 Texas DPS (2011). FAQs: OBDII Emissions Testing. Texas Department of Public Safety, Austin, Texas. 521 https://www.txdps.state.tx.us/rsd/vi/Misc/faq/faq_obdii.htm

522 USDOT (2010) 2009 National Household Travel Survey. U.S. Department of Transportation, Federal 523 Highway Administration. Available at http://nhts.ornl.gov.

524 Weilenmann, M., P. Soltic, C. Saxer, A. Forss, and N. Heeb (2005). Regulated and Nonregulated Diesel 525 and Gasoline Cold Start Emissions at Different Temperatures. Atmospheric Environment 39 (13): 24335262441.

527 Weilenmann, M., J. Favez, and R. Alvarez (2009). Cold-Start emissions of modern passenger cars at 528 different low ambient temperatures and their evolution over vehicle legislation categories. Atmospheric 529 Environment 43(15): 2419-2429.

530 Wisconsin DHS (2012). Methane Fact Sheet. Wisconsin Department of Health Services. 531 http://www.dhs.wisconsin.gov/eh/chemfs/fs/Methane.htm

532 Zhang, S. and W. McMahon (2012). Particulate Emissions for LEV II Light-Duty Gasoline Direct 533 Injection Vehicles. International Journal of Fuels and Lubricants 5 (2): 637-646. 